\title{
Development of a Computational Model for Yoruba Bargaining System
}

\author{
Bello Sururah A. \\ Computer Sc. \& Engn. Dept. \\ Obafemi Awolowo University \\ lle-Ife, Nigeria
}

\author{
lyanda Abimbola $\mathrm{R}$. \\ Computer Sc. \& Engn. Dept. \\ Obafemi Awolowo University \\ Ile-Ife, Nigeria
}

\author{
Adigun Adekunle M. \\ Computer Sc. \& Engn. Dept. \\ Obafemi Awolowo University \\ lle-Ife, Nigeria
}

\begin{abstract}
This paper examines the concept of negotiation in the context of the Yoruba culture to produce a formal representation in form of computational models as a step towards digital preservation of the culture and also integrate this into the growing field of e-commerce. Three of the Bargaining systems of the Yoruba culture was designed using flowchart and use case diagrams. The simulation was done with Java.
\end{abstract}

\section{General Terms}

E-commerce, digital preservation, digital economy, formal methods

\section{Keywords}

Bargaining, Yoruba, Culture, Computational Model.

\section{INTRODUCTION}

In every facet of life directly or indirectly bargaining occurs, whether in an organization (between employers and a group of employees), in the court of law (between a defendant and a prosecutor), in the market (between a buyer and a seller), and almost in all day to day activities. Bargaining is an alternative pricing strategy to fixed prices. Bargaining can be context specific depending on the area of application [1]

Culture denotes the way of life and it plays a fundamental role in every aspect of life of its people. Culture is an integrated system of learned behavior patterns which characterizes the members of the society and which may not be as a result of biological inheritance. Culture can be tangible (which includes the physical things that can be seen or touched e.g. artifacts, arts etc.) or intangible (which includes the nonphysical aspects such as language, customs etc.) [2]. The culture of different region dictates the way of life, dressing, ceremony, trading, language, etc. The ways in which different tribes bargain differs from each other. In North America and Europe bargaining is restricted to expensive or one-of-a-kind items (automobiles, jewelry, art, real estate, etc.) and informal sales settings such as flea markets and garage sales [3]. In other regions of the world bargaining may be the norm even for small commercial transactions. Yoruba culture has its distinct bargaining system and practices mostly the decreased bid method of bargaining. A typical Yoruba will always price goods or services downward before an agreement is reached, whereas the Hausa culture prices upward before reaching an agreement.

One simplified way to decide when it is time to bargain is to break negotiation into two stages: creating value and claiming value [4]. Claiming value is another phrase for bargaining. Some cultures take offence when is perceived that the other side as having started bargaining too soon. This offence is usually as a result of the idea of wanting to first create value for longer before bargaining comes in. This paper examines the concept of negotiation in the context of the Yoruba culture to produce a formal representation in form of computational models as a step towards digital preservation of the culture and also integrate this into the growing field of e-commerce. Cultural heritage is unique and irreplaceable, which places the responsibility of preservation on the current generation. Preservation of cultural heritage for the future is greatly important. A model can accomplish the task of preserving the cultural heritage to ensure the continuous existence of the cultural heritage.

\section{LITERATURE REVIEW}

Historically, Yoruba land overflows into the republic of Benin from the southwest corner of Nigeria. Over 20 million people worldwide speak Yoruba language [5], making it the second largest language group in Africa. Yoruba was formed by nomads and united by a common language and culture; the Yoruba people dominated the area of the west of the Niger River where they established city-states. Each state was headed by the Oba (leader) supported by the council of chiefs. The cultural heritage of Yoruba reflects in every aspect of their life even in trading. There are many types of bargaining systems employed by the Yoruba people for trading. Yoruba operates an open market system; nearly all items are sold in the market. From food stuff to household items to goats even slaves in the days of slave trade.

Negotiation is the process whereby two (or more) individual agents with different criteria, constraints, and preferences, reach a mutually beneficial agreement on a set of issues [5]. Negotiations appear in a multitude of forms, take place in very different situations and are influenced by ethical, cultural and social circumstances [6]. Negotiations is traditionally conducted face to face, later with the advent of electronic communication, fax, mail, telephone etc. were employed. A number of shortcomings has been identified with this; difficulty in management, time consuming and prone to misunderstanding [7], hence, the call for a more sophisticated electronic negotiation. The use of Information Technology has produced formal negotiation procedures and protocols, which has resulted in automated negotiations [9]. In [10], it was pointed out that one of challenges is to illustrate that it is possible to use autonomous agents to completely substitute for humans to automate basic ecommerce activities such as: product brokering, merchant brokering, negotiations, payment etc., in a complete ecommerce scenario, rather than in isolation. According to Error! Reference source not found., computation is closely tied to automation, though it should be noted that automated price negotiations are also governed by mechanisms unknown in advance [12]. 
[13] conceptualize automated negotiations by distinguishing between negotiation protocols (or mechanisms) and negotiation strategies. The protocol defines "rules of encounter" between negotiation participants by specifying the requirements that enable their interaction. The strategy defines the behavior of participants aiming at achieving a desired outcome. This behavior must be consistent with the negotiation protocol, and usually aims at maximizing individual "gains" (not necessarily of monetary value). In [14], negotiation is understood as a process by which a group of agents communicates with each other to come to a mutually acceptable agreement on a price.

In [15], a framework was presented for on-line data mining that supports the identification of the contextual information and providing it on negotiator's demand. Contextual information includes information that can be extracted either from 'historical' data or from data that is coming during the negotiation process. This will enable the data mining system take into consideration the existing knowledge (beliefs) that the negotiation agent poses on that issue and will try to challenge that knowledge. The paper discusses the issues related with timely information discovery and combining the output of the data mining agents into a meaningful and valuable recommendation to the negotiator. The integration of negotiation theory and data mining enables proper discovery and exploitation of negotiation opportunities [16].

[17] presented an algorithm for intelligent selling agents in electronic commerce by investigating the market behavior and the benefits to the sellers under a dynamic price change strategy based on the real-time market bargaining information. It saves the cost of hiring human sales staff to offer bargaining services to online customers. A model was presented in [18] for automated multi-attribute negotiations that autonomous agents can use to negotiate multiple issues in general negotiation contexts with considering Pareto optimality. It was shown that the model is applicable in the situations where agents have nonlinear utility functions and the information is incomplete. The model also simplifies a multi-attribute negotiation that avoids searching the whole negotiation space and considers Pareto optimality at the same time by transforming it into negotiations on a series of base lines.

In [19], the authors explored the development of a digital resource that is amenable to the formal specification of African folktales, specifically the narrative underlying African folktales. The feature of interesting folktales from the point of view of computational rendering as well as a mark-up scheme based on the XML for annotating and cross-indexing the African folktales digital resource collection was discussed. The need for developing a domain specific digital resource was identified. According to [20], research has shown that the knowledge of the identifiable constituents of the Yorùbá heritage domain can be codified into an ontology by the process of ontology engineering using OWL knowledge representation formalism. The resulting digital resources can be made available for global audience downloadable as a digital resource.

\section{BARGAINING SYSTEM}

The concept of "gain" in the Yoruba Economy is very peculiar to the culture as in most cases it is not a monetary gain, rather a fulfillment of each of negotiation participants. This is reflected in the bargaining mechanisms. Several bargaining methods for Yoruba have been identified in literature some of which are listed in the following section:

\subsection{Trade by Barter System}

It is the commonest and oldest form of bargaining and it is therefore termed the bedrock of bargaining. Its system of exchange by which goods or services are exchanged directly without a medium of exchange such as money; the exchange is simply based on the perceived worth of the individual products Error! Reference source not found.. A person can simply exchange a cup of elubo (yam flour) for a cup of garri (cassava flakes) based on the need of the individual party. It is usually bilateral, but may be multilateral i.e. mediated through barter organizations.

\subsection{Decreased Bid Bargaining (A downward price review)}

The bargaining system involves a decreased price negotiation between the buyer and the seller. The seller proposes a price and the buyer offers a much lower price than the proposed price by the seller. In this system, the buyer is so persistent about the pricing of the good or service which is in a decreased trend. As usual a buyer will want to pay for a commodity at a minimum price. Also the duration of the bargaining process is dependent on both the buyer and the seller, as the seller wants to make a good profit as well as sell at a high price and the buyer want to buy at the lowest price. This condition brings about a lengthy bargaining process between the buyer and the seller. Each of the parties (the buyer and seller) has strategies in which the best strategy gives in to other (survival of the fittest).

\subsection{Bargaining by Social Status Class}

The social class of a buyer in the market sometimes dictates the price of a particular commodity or service. People are generally classified into three social levels based on their lineage: the lower class, the middle class and the high class. Typically, the sellers in the market have a distinct way of measuring the social class of the different buyers. Sometimes the sellers used the appearance of a buyer as way of determining the class of buyer. The seller proposed the price of a commodity or service based on the class of the buyer. Higher class indicates higher price, middle class depicts average price and lower class indicates lower prices.

Apart from these three, the status of a buyer can also influence the price. A prince or princess in Yoruba land may not be required to pay for items in market, whereas other citizens pay for same item. This is used as a mark of respect or to demonstrate acceptability or love to the ruling class.

In Yoruba land it is believed that a certain measure in terms of quantity belongs to different set of people. E.g. typically, in the core Yoruba setting, yam tubers are sold in six, if a seller put the tubers in three then, it is not meant for the general populace then only a particular class in the society can purchase it.

\section{DESIGN OF YORUBA BARGAINING SYSTEM (YBS)}

The designs for the YBS was done using flowchart, algorithm and use case diagram diagrams. The design contains the detailed representation of the YBS model.

Figure 1 depicts the algorithm for the trade by barter system respectively. The model for the trade by barter system consists of two agents (Agent1 and Agent2). Each of the agents has a product it wants to exchange for another product. 
Start:

1. Agent 1 is an entity that possesses Product land is interested in exchanging Product1

2. Agent 2 is another entity that possesses product 2 and also ready to exchange

3. Select product1 for Agent1 and product 2 for Agent 2 from the market database

4. Generate random numbers for agentland agent 2 to bargain

5. If random numbers selected are even: Exchange

6. Else:

No exchange

End process

Fig 1: Algorithm for Trade by Barter System

The design was implemented using the random number algorithm. Each of the agents selects a product from the database. The selection of the product will be random based on the details with which the database is populated. After the product selection, two random numbers are generated. This is to determine the perceived needs of each of the agents. When an even number is generated, it means the agent is interested in the product. During the bargaining process, the only condition that will exchange the products between the agents is when the random number generated for both agents are even i.e. each agent has an interest in the product of the other agent.

The use case for the Trade by Barter System is shown in Figure 2. Each of the agents interacting with the five main actions. The action includes select produce from database, generate random numbers, bargain to trade, exchange and no exchange. Each of the actions works the same way as previously described.

In Figure 3, before the bargaining process begins, the Agent1 (seller) selects the product to sell to the Agent2 (buyer) from the market database. Agentl (seller) has its own strategies for selling the product to the Agent2 (buyer). The variable Smin and Smax represent the minimum and the maximum price Agent1 (seller) can sell the product to Agent2 (buyer). Variable $b$ represents the bargain price at each round of the bargain. At the start of the bargaining process, Smax equals $b$. Agent2 (buyer) proposes a price which is less than that of the

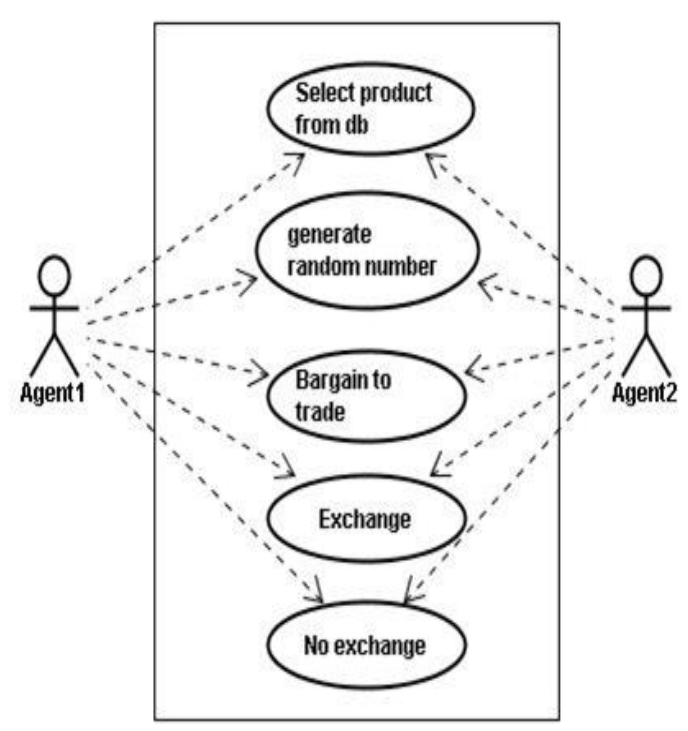

Fig 2: Use Case Diagram for Trade by Barter System

The decreased bid bargaining is also modeled using the Figures 3. The model consists of two agents (Agentl and Agent2). The Agent1 represents seller and Agent 2 depicts the buyer of the product. Agentl simply query the market database to select which product to sell. The market database contains the product name, the cost price and the proposed selling price.

Start:

1. Agent 1 is the Product Seller

2. Agent 2 is the product Buyer

3. Agent1 selects product from the market database

4. Start bargaining between agent1 and agent 2

5. If Smin is the minimum price acceptable to Agent 1

6. $\quad b$ is the maximum proposed price from the Agent 2

7. Bmin is the min price Agent 2 can pay

8. If Smin $>b$ and $b<=\operatorname{Smax}$ and $b>=B \min$ :

Agent1 sells to Agent 2

9. Else:

Re-bargain between agent 1 and agent 2

End process

Fig 3: Algorithm for the Decrease Bid System

In Figure 3, before the bargaining process begins, the Agent1 (seller) selects the product to sell to the Agent2 (buyer) from the market database. Agentl (seller) has its own strategies for selling the product to the Agent2 (buyer). The variable Smin and Smax represent the minimum and the maximum price Agent1 (seller) can sell the product to Agent2 (buyer). Variable $b$ represents the bargain price at each round of the bargain. At the start of the bargaining process, Smax equals $b$. Agent2 (buyer) proposes a price which is less than that of the Agent1 (seller). The buyer on its own also has a maximum and minimum price he can buy the product which are Bmin and Bmax respectively. The only condition the Agent1 sells to Agent 2 is when $b$ the bargain price falls within the range of Smin and Smax. Reduction_Scale represents the amount with which $b$ decreases. 
Here, Agentl interacts with five actions which include: select product from database, proposed price for the product, bargain for the product, sell the product and not selling. Agent2 interacts with three actions which include: bargain for the product, sell the product and not selling. At the start of the system, Agentl selects the product from the database along with the price, and then proposes a price to Agent 2 and Agent 2 bargains for the product. If the price proposed by Agent 2 during the negotiation process fall within Smin and Smax, then Agentl sells the product to Agent2. Bargaining by class system is modeled using Figures 4 and 5.

Start:

1. Agent 1 is the Product Seller

2. Agent 1 define class for buyers (Low, Middle and High)

3. Agent 1 assign price range to the defined classes

4. Agent1 selects buyer from the market database

5. Generate the buyer's class

6. If class is low class:

Bargaining between agentl and buyer
If Smin $>b$ and $b<=$ Smax and
$b>=$ Bmin:
ii. $\quad$ Else: $\quad$ Seller sells to buyer
Bargain between agentl

and buyer

7. Else if class is middle class :

Bargain between agent1 and buyer

i. $\quad$ If $\operatorname{Smin}>b$ and $b<=$ Smax and $b>=$ Bmin:

ii. Else:

Seller sells to buyer

Bargain between agent1

and buyer

8. Else if class is high class:

Bargain between agentl and buyer

i. If Smin $>b$ and $b<=\operatorname{Smax}$ and $B>=$

Bmin:

ii. $\quad$ Else:

Seller sell to buyer

Bargain between agent1

and buyer

End process

Fig 4: Algorithm for Bargaining by Class system

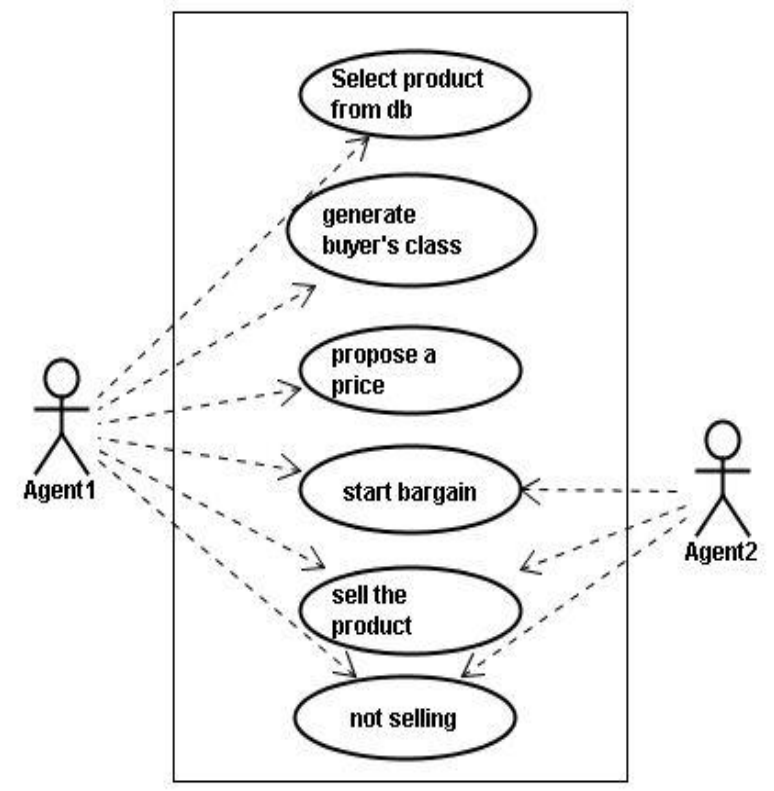

Fig 5: Use Case Diagram for Bargaining by Class System

The model for the bargaining by class system uses two agents (Agent1 and Agent2) as others. Agent1 calls a buyer's class to determine the buyer's class represented by the high class, middle class and low class. Each of the classes of buyer has an equal chance of being chosen. The method of identification of the buyer's class is based on the physical appearance of the buyer. The number of bargaining rounds each class of buyer can go through differs depending on their class. The class of the buyer is a determining factor of the selling price of the Agent1 (seller).

For example, Agent1 can decide to increase the price by a factor $F p$ i.e. $(F p+C . P)$, where $F p$ and C.P denotes the addictive factor and the cost price of the product. S.P (selling price) relates to the $F p$ and $C . P$ by $S . P=F p+C . P$. The starting price during the bargaining process (Smax) is dependent on the class of the buyer and $F p$. The only price Agent1 (seller) will sell to Agent2 (buyer) is when the proposed price by the Agen2 (buyer) fall within the range of Smin and Smax. The bargaining process that occurs between different classes of buyer and the seller is distinct as well as the number of times bargaining process occurs. The pricing strategy used in decreased bid is applied.

In Figure 4, the action generate buyer's class trigger propose a price action. Depending on the generated class of buyer the price proposed by Agent1 decreases or increases as appropriate. The seller generates a buyer's class and proposes a price for the product. The buyer bargains using class, the seller decides to sell the product or otherwise.

\section{IMPLEMENTATION OF YORUBA BARGAINING SYSTEM}

The interface consists of the file menu, help menu, the bargaining screen, the agent label, product label, the image product label and the start button. The file menu provides an avenue to choose within the three bargaining system. The bargaining screen shows the details of the transaction between the two agents. The start button below the bargaining screen starts the bargaining process between the two agents. 
In the implementation of the trade by barter system (Figure 6), the bargaining screen gives the detailed summary of the negotiation between the two agents. There are two agents interacting as described in the system design. The two agents (Agent 1 and Agent 2) exchanged their product based on their perceived need of the product. The product to exchange with will be selected from the market database. There are two products (Agent 1 has product: Egunsi while Agent 2 has product: Eja) and four possible conditions that can occur between the two agents (Agent 1 and Agent 2).

i. Either both are not interested in the product.

ii. Agent 1 is interested and Agent 2 is not.

iii. Agent 2 is interested and Agent 1 is not.

iv. Both of them are interested in the product.

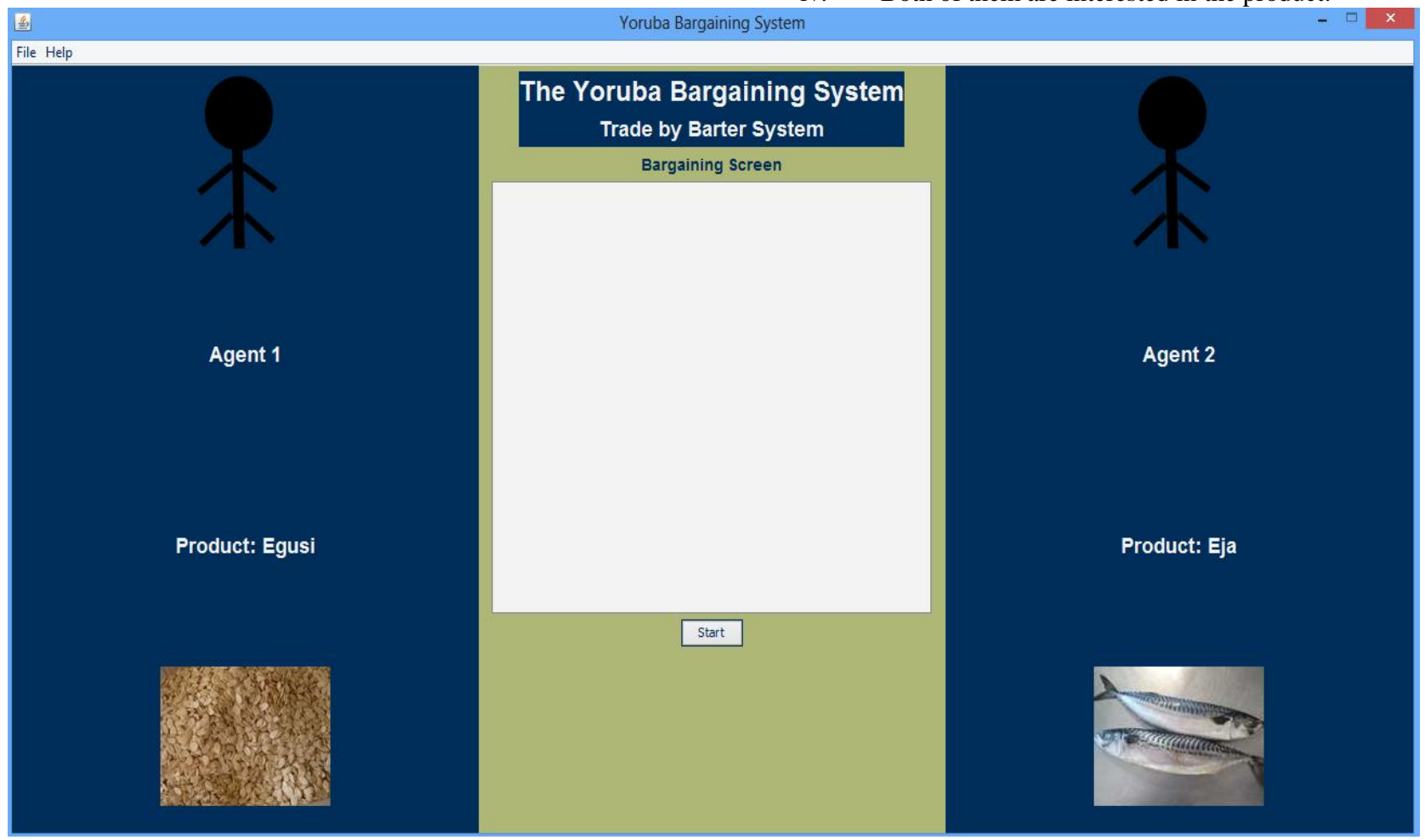

Fig 6: Initial Trade by Barter Bargaining System

When both agents are interested, an agreement is reached, the product is exchanged which will be visible on the interface design through the swapping of the image label and product label.

For the decreased bid system, the start button initializes the negotiation process between the buyer and the seller. The seller agent selects the product and the cost price of the product from the market database. Before start of the negotiation process, the seller agent adds an addictive factor to the cost price of the product, also there is a minimum price Smin and the maximum price Smax the seller agent can sell unknown to the buyer. The buyer agent starts the negotiation process by asking for the price of the product. The buyer agent proposes a price lower price than the initial price. The main objective of the buyer agent is to get the product at the barest minimum Bmin. The proposed price by the buyer will be accepted by seller if the price falls between Smin and Smax, the price is rejected. The bargaining screen as shown in Figure 7 displays the detailed summary of the negotiation between the buyer and the seller.

For the bargaining by class shown in Figure 8, three classes of buyer (the low class, middle class and the high class) were assumed. The seller agent determines the class of buyer based on the characteristics or features of the buyer. The selling price for the product will be determined by the characteristics or feature of the buyer i.e. the selling price will be low for low class buyer, average for middle class buyer and high for high class buyer. When the class of buyer has been determined, the seller agent selects the product and cost price from the database. Each class of buyer has a number of negotiation rounds they can go through with the seller. Before start of the negotiation process, the seller agent adds an addictive factor to the cost price of the product, also there is a minimum price.

Smin and the maximum price Smax the seller agent can sell unknown to the buyer. The bargaining power of each class of buyer differs from each other. The low class buyer has the highest bargaining power i.e. the low class i.e. the low class buyer can undergo the highest negotiation rounds. The low class buyer negotiates the price of garri with the seller and bought the product at the barest minimum. The middle class buyer can negotiate optimally with the seller i.e. the bargaining power is average. The high class buyer has the lowest bargaining power.

\section{CONCLUSION}

Three of the Yoruba Bargaining System has been modeled computationally. This implies that the system can be employed in the growing e-commerce field. This will also assist in preserving one of the rich aspect of Yoruba cultural heritage. 


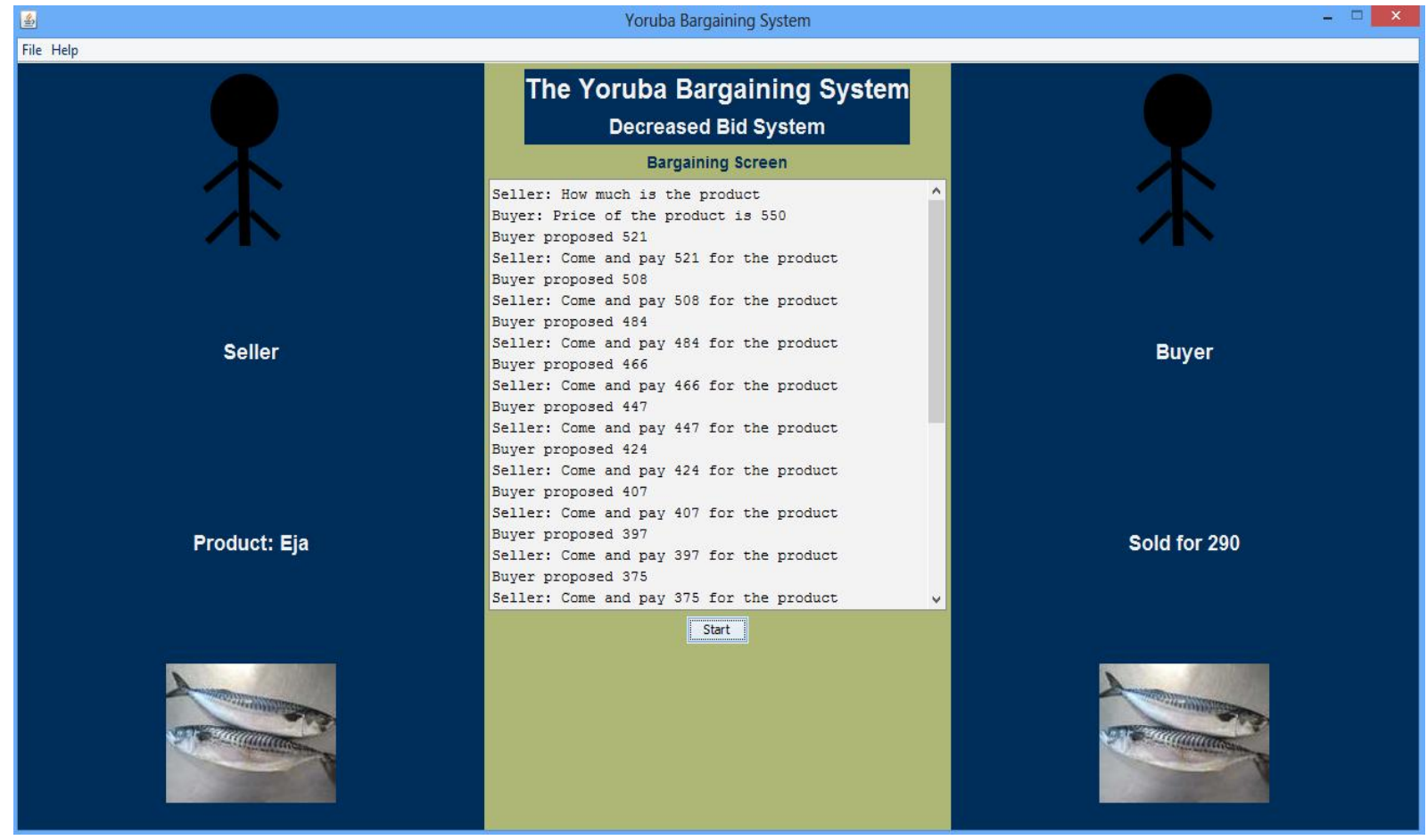

Fig 7: Decreased Bid Bargaining System

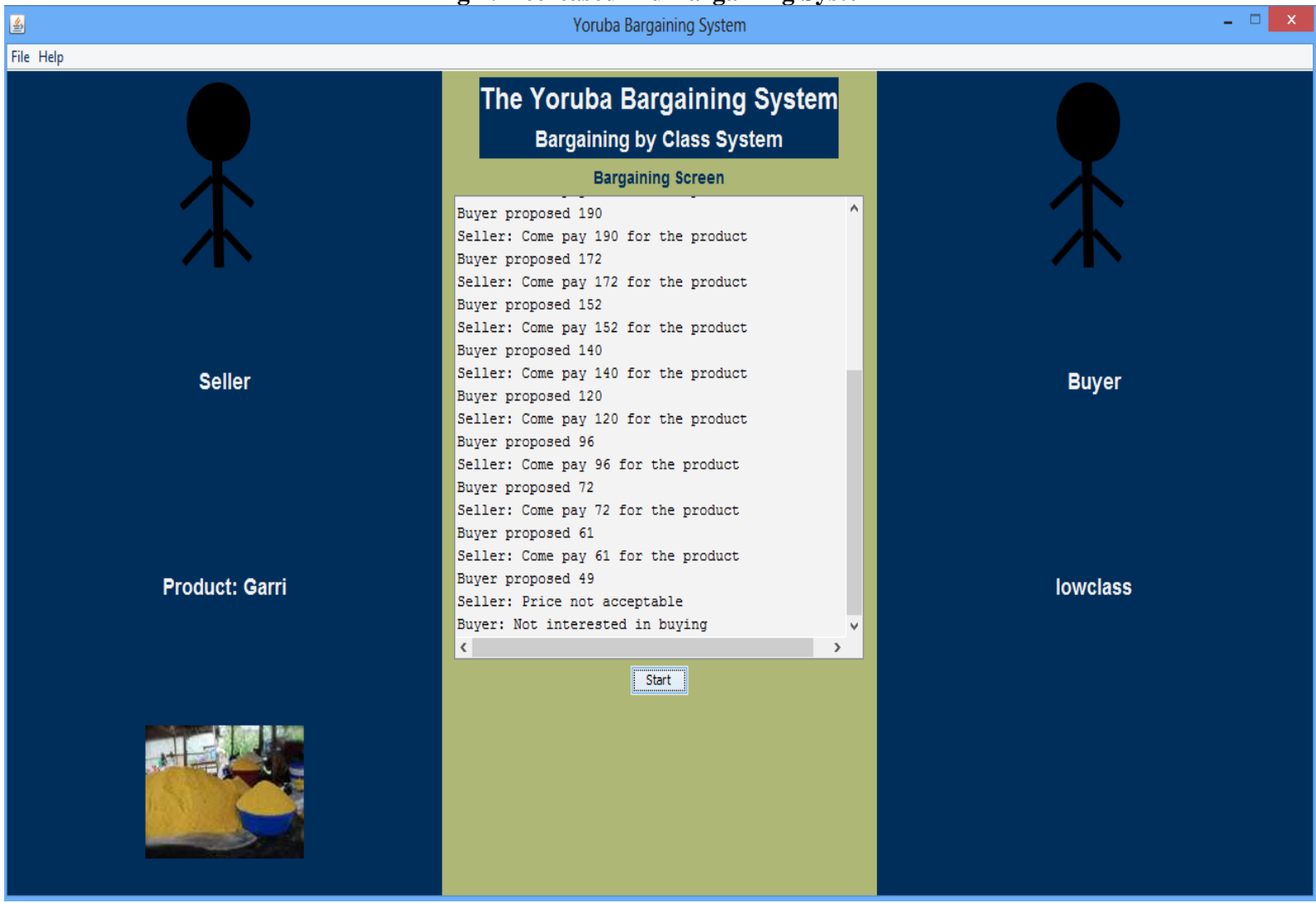

Fig 8: Class Bargaining System

\section{REFERENCES}

[1] The President and Fellows of Harvard College. Bargaining http://www.pon.harvard.edu/tag/bargaining-table/. (2016). Assessed Date: February, 2016

[2] J. E. Doughan. 2012. The Use of Art in the Preservation of History: A Case Study of Winneba and Mankessim. MPhil Thesis.. Kwame Nkrumah University of Science and Technology. Ghana

[3] K. Sycara. and T. Dai, Agent reasoning in negotiation. 2010. In Handbook of Group Decision and Negotiation (pp. 437-451). Springer Netherlands.

[4] J. S. Olson. 1996. The peoples of Africa: an ethnohistorical dictionary. Greenwood Publishing Group. 
[5] S. J. Simoff. Mining'Living. 2002. "Data-Providing Context Information to a Negotiation Process". Lecture Notes in Computer Science, S. (2002):521-526

[6] I. Rahwan, R. Kowalczyk, and H. H. Pham. 2002. "Intelligent agents for automated one-to-many ecommerce negotiation". In Australian Computer Science Communications. 24(1): 197-204. Australian Computer Society, Inc.

[7] L. Alem, R. Kowalczyk and M. Lee. 2002. "Supporting Electronic Negotiation for Intelligent Trading." Managing Business with Electronic Commerce: Issues and Trends (2002): 1-16.

[8] M. Bichler, G. Kersten and S. Strecker. 2003. "Towards a Structured Design of Electronic Negotiations" Group Decision and Negotiation. 12 (4): 311-335, Kluwer Academic Publishers. Printed in the Netherlands

[9] I. Marsa-Maestre, M. A. Lopez-Carmona, T. Ito, M. Zhang, Q. Bai and K. Fujita. 2014. Novel Insights in Agent-based Complex Automated Negotiation, Vol. 535. Springer.

[10] L. Thompson. 2001. The Mind and Heart of the Negotiator. Upper Saddle River, NJ: Prentice Hall.

[11] C. Bădică, M. Ganzha, M. Paprzycki and A. Pirvănescu. 2005. Combining rule-based and plug-in components in agents for flexible dynamic negotiations. Lecture notes in computer science, 3690 , p.555

[12] B. W. Arden. 1983. What can be automated: Computer Science and Engineering Research Study (COSERS). MIT Press.

[13] C. Bădică, A. Bădiţă, M. Ganzha, A. Iordache, and M. Paprzycki. 2005, November. Rule-Based framework for automated negotiation: initial implementation. In International Workshop on Rules and Rule Markup
Languages for the Semantic Web (pp. 193-198). Springer, Berlin, Heidelberg.

[14] C. Bădică, A. Bădiţă and M. Ganzha. 2006. "Implementing rule based mechanisms for agent based price negotiations" SAC'06 April 23-27, , Dijon, France Copyright 2006 ACM 1595931082/ 06/0004

[15] A. R. Lomuscio, M. Wooldridge and N.R. Jennings. 1991. A classification scheme for negotiation in electronic commerce. In: F. Dignum, C. Sierra (Eds.): Agent Mediated Electronic Commerce: The European AgentLink Perspective, LNCS, Springer Verlag (2002) 19-33.

[16] B. An, K. M. Sim, L. G. Tang, S. Q. Li and D. J. Cheng. 2006. Continuous-time negotiation mechanism for software agents. Systems, Man, and Cybernetics, Part B: Cybernetics, IEEE Transactions on, 36(6), 1261-1272

[17] Y.P. Sheng. 2004. A Dynamic and Adaptive Bargaining Algorithm for Intelligent Selling Agents in Electronic Commerce." Int. J. Comput. Syst. Signal 5.1 (2004): $43-$ 57.

[18] G. Lai, K. Sycara, and C. Li. 2007. A pareto optimal model for automated multi-attribute negotiations. In Proceedings of the 6th international joint conference on Autonomous agents and multiagent systems (p. 246). ACM.

[19] D. O. Ninan and O. A. Odejobi. Theoretical Issues in the Computational Modeling of Yorùbá Narratives. Workshop on Computational Models of Narrative 4-6 August 2013. Universität Hamburg, Hamburg, Germany

[20] J.A. Hassan, O.A. Odéjóbí, B.A. Ògúnfolákàn and A. Adéjùwón A. 2013. Ontology Engineering in Yorùbá Cultural Heritage Domain. Afr J. of Comp \& ICTs. 1 6(5):181-198 